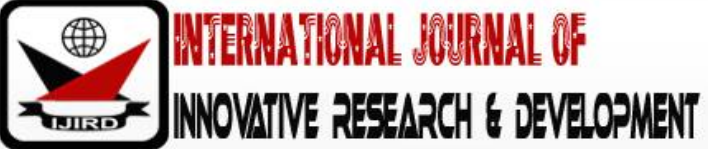

ISSN 2278 - 0211 (Online)

\section{Human Capital, Social Capital and Employment in the Era of Artificial Intelligence}

\author{
Haojian Dui \\ Master Student, School of Labor and Economics, \\ Capital University of Economics and Business, China
}

\begin{abstract}
:
The fourth industrial revolution represented by technologies such as artificial intelligence and big data has kicked off. Mankind is undergoing an all-round change. In this era where opportunities and challenges coexist, the labor market will also usher in tremendous changes. In this context, I formulated this research plan to explore the impact of human capital on employment in the era of artificial intelligence. This study intends to achieve the following goals:1. Clarify the effect and mechanism of human capital and social capital's influence on workers' professional artificial intelligence in the era of artificial intelligence.2. Clarify the effect and mechanism of human capital and social capital on the employment quality of workers in the era of artificial intelligence.3. Based on the conclusions drawn, in the era of artificial intelligence, how to respond to changes in the labor market and provide targeted suggestions for human capital investment; Put forward countermeasures for the government in the era of artificial intelligence to stabilize the labor market and ensure employment; Provide strategies for related companies on how to coordinate the relationship between artificial intelligence and workers in the era of artificial intelligence.
\end{abstract}

Keywords: Artificial intelligence, human capital, social capital, employment

\section{Argument Basis}

In 1956, the concept of artificial intelligence was first publicly proposed at the Dartmouth Conference, and the discipline of artificial intelligence was officially born. For decades, artificial intelligence has been advancing in twists and turns. However, since 2011, with the advancement of information technologies such as the Internet, the Internet of Things, big data, and cloud computing, artificial intelligence has continuously broken through technical bottlenecks and ushered in a leapfrog development.

Since 2015, China has successively formulated and implemented national-level strategic plans such as 'Made in China 2025', 'Internet +', and 'New Generation Artificial Intelligence Development Plan', and deployed artificial intelligence as a national key strategy. According to the 'China's New Generation Artificial Intelligence Technology Industry Development Report (2019)' released by the China Academy of New Generation Artificial Intelligence Development Strategy, As of February 28, 2019, the report detected 745 artificial intelligence companies, second only to the United States. People's attention to artificial intelligence has also reached a new peak. There are not only a large number of supporters, but also catastrophists. The potential impact of artificial intelligence on employment is also the focus of debate in all sectors of society. Many scholars believe that artificial intelligence will cause a large number of unemployment ${ }^{[i][i i][i i i], ~ a n d ~ s o m e ~ s c h o l a r s ~ h o l d ~ d i f f e r e n t ~ v i e w s:[i v] ~}$

Replacing repetitive human labor with machines is the core of technological change since the industrial revolution[v][vi], as one of the representative technologies of the fourth industrial revolution, artificial intelligence not only has more powerful computing and storage capabilities, but more importantly, it has reasoning and learning capabilities that previous machines did not have. As the late MIT professor Winston said: 'Artificial intelligence is the study of how to make computers do intelligent tasks that only humans could do in the past.' Therefore, the impact of artificial intelligence on the labor market will be disruptive. A large number of scholars have pointed out that artificial intelligence has an obvious substitution effect on labor. Artificial intelligence will replace a large number of existing laborers' jobs and make a large number of laborers unemployed, which will cause many problems. For example: changes in the nature of the work of workers; the income gap will widen rapidly, accompanied by political and economic problems[vii]; cause people's anxiety, etc. At the same time, many studies have pointed out that while artificial intelligence has a substitution effect on employment, it also has a creative effect.[viii][ix][x]

It can be seen that the employment issue in the era of artificial intelligence requires us to think deeply, and human capital and social capital, as important factors affecting employment, have been widely recognized by the academic community. Many studies have shown that human capital is the key to a company's competitive advantage[xi][xi], It also plays an important role in employment. For example, human capital has a significant impact on the employment status and quality of workers[xii][xiv]; The ability to express emotions and regulate emotions and other non-cognitive aspects also has 
a significant positive relationship with the quality of employment ${ }^{[\mathrm{xv}]}$; Individual's cognitive ability affects employees' salary and career promotion. ${ }^{[x v i] A n d ~ m o r e ~ a n d ~ m o r e ~ s c h o l a r s ~ r e a l i z e ~ t h a t ~ s o c i a l ~ c a p i t a l ~ h a s ~ a n ~ i m p o r t a n t ~ i m p a c t ~ o n ~}$ employment.[xvii][xviii]

In short, in order to cope with the disruptive impact of artificial intelligence on the labor market and ensure the quality of employment of employees, this study intends to use CFPS data to empirically analyze the impact of human capital and social capital on employment in the artificial intelligence era, which is the artificial intelligence era The labor market provides new countermeasures.

\section{Research Content and Objectives}

\subsection{Research Content}

\subsubsection{The Impact of Artificial Intelligence on the Labor Market}

The impact of scientific and technological progress on the labor market has always been the focus of the academic community. Since the period of the first industrial revolution, every technological revolution in history has led to a large number of labor employment transfers, and 'machine substitution' has repeatedly caused workers' anxiety.

In recent years, many scholars have conducted research on this. Gali (1999) analyzed data from the Group of Seven (G7),It also analyzes the permanent and temporary impacts of technology, and points out that for most countries, a positive technological impact will cause employment to fall. [xix]Some researchers have reached similar conclusions through empirical analysis[xx][xxi], But there are also some studies that believe that a positive technological shock will increase employment. [xxi][xxiii]Some scholars have analyzed the source of difference in this result, and believe that this difference is mainly due to the choice of variables and the difference in sample data.[xxiv][xxv]Chinese scholars have also made contributions in this field. Ming Juan and Wang Wenfu conducted empirical analysis using China's data from 1992 to 2007, point out that in China, a positive technological shock will cause employment to decline briefly, and then continue to rise to its original state.[xxvi]Similarly, Su Jian and Chen Yang believe that in the short term, technological progress may cause structural unemployment, but with the adjustment of the industrial structure and workers themselves, employment will gradually recover or even increase.[xxvii]

As mentioned above, artificial intelligence has many abilities that machines did not have in the past. It is considered to be the automation of human thinking activities[xxviii] thinking machines[xix] machines with perception, reasoning and action capabilities. ${ }^{[\mathrm{xx} x}$ Therefore, unlike previous technological changes, artificial intelligence will have a more profound impact on the labor market.

In order to assess the impact of artificial intelligence on the American labor market, Frey \& Osborne (2017) used the 0*NET database developed by the U.S. Department of Labor and combined subjective and objective scoring methods to assess 702 occupations in the United States. Computerized probability is estimated.[xxxi]Felten et al. (2019) created the AI Occupational Impact Index (AIOI).[xxxii]

In this part of the content, this study intends to combine the above two sets of data to estimate the effects of various occupations in China affected by artificial intelligence and form the degree of professional artificial intelligence influence.

\subsection{The Impact of Human Capital and Social Capital on Employment}

According to the definition of human capital by Li Xiaoman and Zeng Xiangquan (2012) based on the new human capital theory, competence is its core and consists of cognitive and non-cognitive capabilities.[xxxii]In China's previous studies on the impact of human capital on employment, non-cognitive abilities are often overlooked compared to cognitive abilities. Scholars have only begun to focus on this field in recent years.Cheng Fei (2013) combed through the literature and found that non-cognitive abilities have an important impact on income and also affect other performances of workers. ${ }^{[x x x i v]} \mathrm{Hu}$ Bowen (2017) found through empirical research that the impact of non-cognitive ability on the income of employees is very close to the length of education, while the impact on wage differences is even greater.[xxxv]Sheng Weiyan and Hu Qiuyang (2019) found that both cognitive ability and non-cognitive ability have a positive impact on income, and non-cognitive ability can significantly increase the skill premium level, while cognitive ability cannot.[xxxvi]

In addition to human capital, the relationship between social capital and employment has gradually attracted scholars' attention.Xu Xiaojun (2002) believes that human capital and social capital are dual mechanisms that affect employment, and when workers have a bachelor's degree or below, social capital has a greater impact, and this impact will vary with the level of social education.[xxxvii]Zheng Jie (2004) found through empirical research that social capital has a significant impact on the employment intention, target salary, and employment success rate of college graduates.[xxxvii]Lai Desheng et al. (2012) found that the impact of human capital and social capital on the employment of college students has both substitution and complementary relations. ${ }^{[\mathrm{xxxix}]}$

In this part of the content, based on previous research, combined with the background of the new era of artificial intelligence, through empirical research methods, a detailed analysis of the relationship between human capital and social capital and the impact of professional artificial intelligence and employment quality. First, it will analyze the impact of human capital and social capital, including cognitive and non-cognitive capabilities, on the impact of professional artificial intelligence. Then analyze the relationship between human capital and social capital and employment quality. 


\subsection{Research Objectives}

This research intends to achieve the following goals through the analysis of the above content:

- Clarify the effect and mechanism of human capital and social capital's influence on workers' professional artificial intelligence in the era of artificial intelligence.

- Clarify the effect and mechanism of human capital and social capital on the employment quality of workers in the era of artificial intelligence.

- Based on the conclusions drawn, provide targeted suggestions on how workers respond to changes in the labor market and invest in human capital in the era of artificial intelligence;put forward countermeasures for the government in the era of artificial intelligence to stabilize the labor market and ensure employment;provide strategies for related companies on how to coordinate the relationship between artificial intelligence and workers in the era of artificial intelligence.

\section{Research Plan Design and Feasibility Analysis}

\subsection{Variable Introduction}

\subsubsection{Professional AI Impact}

The variable of the impact of occupational artificial intelligence used in this study is proposed to be based on the conclusions of Frey \& Osborne (2017) [xxxi]and Felten et al. (2019) [xxxi], combined with the CFPS database The occupation is calculated.

The main reason for combining the results of the two studies instead of choosing one is that the measurement standards of the two are different. The estimation method of the former is based on the objective scores of the perception and operation ability, creativity and social intelligence of each occupation provided by the O*NET database of the U.S. Department of Labor, and the subjective assignment of various occupations by experts from Oxford University, combining subjective and Two objective methods estimate the probability of computerization. The latter's estimation method is: According to the progress data of artificial intelligence in specific applications provided by the Electronic Frontier Foundation (EFF),Such as image recognition, translation, ability to play strategic games, and work ability, etc., to estimate the artificial intelligence occupational impact (AIOI) of each occupation in the U.S. Department of Labor O*NET database, which is calculated from the perspective of micro-personal ability Way to make up for the deficiencies of previous research.

In this study, the author will average the results of the above two studies to obtain the artificial intelligence influence of each occupation, and match it with the occupations in CFPS to obtain the occupational artificial intelligence influence used in this article Degree of variable.

\subsection{Employment Quality}

According to the Organization for Economic Cooperation and Development (OECD) pointed out in 2016, the quality of employment should be considered from three aspects: Quality of income, work stability, and quality of work environment.[xl]Therefore, based on the data provided by CFPS, this study selects 'total income from work (yuan/year)' as the proxy variable for income quality, and 'whether to sign a contract' and 'job security (insurance payment)' as proxy variables for job stability , 'Work environment satisfaction' as a proxy variable of the work environment.

\subsection{Human Capital}

In this study, human capital is represented by cognitive ability and non-cognitive ability. Among them, in terms of cognitive ability, this study intends to use 'respondents' math test scores' and 'respondents' word test scores' to represent the crystal intelligence of the respondents. For the scores of the word test, these questions are arranged in order from easy to difficult, and CFPS will determine the starting point for the questions and calculate the score according to the education level of the respondent. In terms of non-cognitive abilities, we used the methods of Huang Guoying and Xie Yu (2017) [xli] and Sheng Weiyan and Hu Qiuyang (2019) [xxxvi] to compare the CFPS interviewer's observation data on the 'respondent's degree of cooperation with the survey, the interviewee's The level of waiting, the interviewee's interest in the survey, the credibility of the interviewee's answer, and the interviewee's language ability' are averaged to construct proxy variables for the interviewee's non-cognitive ability.

\subsection{Social Capital}

This research draws on the practice of Zhou Guangsu et al. (2014)[xlii], Select the 'reward and exchange of gifts' in the CFPS data, that is, the gifts and gifts (equivalent to RMB) sent or received by the family that year and 'whether you are currently a member of an organization' as the proxy variables of social capital.

\subsection{Proposed Method}

When analyzing the impact of human capital and social capital on professional artificial intelligence, the model to be used is as follows:

AII $=\alpha_{0}+\alpha_{1}$ HumanCapital $+\alpha_{2}$ SocialCapital $+\alpha_{3} X+\mu$

In formula (1),AIIrepresents the impact of professional artificial intelligence,HumanCapitalrepresents the proxy variable of human capital, SocialCapitalrepresents the proxy variable of social capital, $X$ contains other control variables, such 
as gender, age, urban and rural category, household registration, etc., $\alpha_{0}$ is a constant term, $\alpha_{1}$ represents the influence coefficient of human capital on employment types, $\alpha_{2}$ represents the influence coefficient of social capital on employment types, $\alpha_{3}$ represents the influence coefficient of other control variables on the type of employment, and $\mu$ is the residual value.

When analyzing the effects of human capital and social capital on the employment quality of workers, this article intends to use a hierarchical linear model (also called a multilevel linear model) for analysis. The reason for choosing the hierarchical linear model is that when analyzing employment quality, we not only pay attention to the impact of human capital and social capital on the employment quality of workers, but also the impact of different occupations on employment quality. The hierarchical linear model can help We achieve this goal, and employment is multi-layered, and the observation data has a nested relationship in units.

But before really using the hierarchical linear model, you need to test the applicability of the data, and first calculate whether the correlation coefficient within the group is large enough (usually bounded by 0.1).If it is large enough, it means that the macro level has a certain degree of explanatory power for the individual level, and it is suitable to use the hierarchical linear model. If it is not large enough, the single-level linear model can be used directly.

In the analysis process of this part, if the hierarchical linear model is applied, the model used is as follows:

The first layer model:

JobQuality $_{i j}=\beta_{0 j}+\beta_{1 j}$ HumanCapital $_{i j}+\beta_{2 j}$ SocialCapital $_{i j}+\beta_{3 j} X_{i j}+\mu_{i j}$ (2)

The second layer model:

$\beta_{0 j}=\gamma_{00}+\gamma_{01} A I I_{j}$ (3)

$\beta_{1 j}=\gamma_{10}+\gamma_{11} A I I_{j}$ (4)

$\beta_{2 j}=\gamma_{20}+\gamma_{21} A I I_{j}$ (5)

$\beta_{3 j}=\gamma_{30}$ (6)

Consolidation model:

JobQuality $_{i j}=$

$\gamma_{00}+\gamma_{01}$ AII $_{j}+\gamma_{10}$ HumanCapital $_{i j}+\gamma_{11}$ AII $_{j}$ HumanCapital $_{i j}+\gamma_{20}$ SocialCapital $_{i j}+\gamma_{21}$ AII $_{j}$ SocialCapital $_{i j}+$ $\gamma_{30} X_{i j}+\mu_{i j}(7)$

In formulas (2) to (7), i represents the $\mathrm{i}$-th employed person, and $\mathrm{j}$ represents the $\mathrm{j}$-th occupation.JobQuality $y_{i j}$ represents the employment quality of the i-th employee in the j-th occupation, $\gamma_{00}$ is the intercept term, $\gamma_{01}, \gamma_{10}, \gamma_{20}, \gamma_{30}$ respectively represent the main effect of each variable on the quality of employment, $\gamma_{11}$, $\gamma_{21}$ indicate the interactive effect of personal variables and the influence of professional artificial intelligence.

In addition, in order to make the conclusions more robust, this study intends to use the data in the CGSS database for robustness testing.

\subsection{Feasibility Analysis}

First of all, in terms of the selection of key variables, this study has borrowed from the domestic and foreign literature with a high citation rate, and its rationality has been widely verified. Secondly, based on the review of the literature, the theoretical basis to be adopted in this study is reliable and the research methods are mature. In addition, in terms of data, CFPS data adopts a multi-stage, implicit stratification and systematic probability sampling method proportional to the population size. The data has good randomness and national representativeness, and has been widely verified. Therefore, it can be considered that this research plan has strong feasibility.

\section{References}

i. Nilsson N J. Artificial intelligence, employment, and income[J]. AI magazine, 1984, 5(2): 5-5.

ii. Makridakis S. The forthcoming Artificial Intelligence (AI) revolution: Its impact on society and firms[J]. Futures, 2017, 90: 46-60.

iii. Rotman D. How technology is destroying jobs[J]. Technology Review, 2013, 16(4): 28-35.

iv. Acemoglu D, Restrepo P. Artificial intelligence, automation and work[R]. National Bureau of Economic Research, 2018.

v. Mokyr J. The lever of riches: Technological creativity and economic progress[M]. Oxford University Press, 1992.

vi. Goldin C, Katz L F. The origins of technology-skill complementarity[J]. The Quarterly journal of economics, 1998, 113(3): 693-732.

vii. Korinek A, Stiglitz J E. Artificial intelligence and its implications for income distribution and unemployment[R]. National Bureau of Economic Research, 2017.

viii. Zeng Xiangquan,XuChangjie.The impact of the new technological revolution on the labor market[J].Exploration and Contention,2015(08):32-35.

ix. DuanHaiying,GuoYuanyuan.A Review of the Employment Effects of Artificial Intelligence[J].Economic System Reform,2018(03):187-193.

x. Yang Weiguo,QiuZitong,WuQingjun.A review of the employment effects of artificial intelligence applications[J].China Population Science,2018(05):109-119+128.

xi. Felin T, Hesterly W S. The knowledge-based view, nested heterogeneity, and new value creation: Philosophical considerations on the locus of knowledge[J]. Academy of management review, 2007, 32(1): 195-218. 
xii. Abell P,Felin T, Foss N. Building micro-foundations for the routines, capabilities, and performance links[J]. Managerial and decision economics, 2008, 29(6): 489-502.

xiii. Chen Chengwen, Tan Rihui. The relationship between human capital and the employment of college graduates: an empirical study based on the 2003 and 2004 college graduates[J]. Higher Education Research, 2004, 25(6): 31-35.

xiv. González-Romá V, Gamboa J P, Peiró J M. University graduates' employability, employment status, and job quality[J]. Journal of Career Development, 2018, 45(2): 132-149.

xv. Yao Yanhong, Zhang Jing. An Empirical Study on the Influence of Emotional Intelligence on the Employment Quality of College Students[J]. Modern University Education, 2010 (6).

xvi. Ng T W H, Feldman D C. Human capital and objective indicators of career success: The mediating effects of cognitive ability and conscientiousness[J]. Journal of Occupational and Organizational Psychology, 2010, 83(1): 207-235.

xvii. Fernandez R M, Castilla E J, Moore P. Social capital at work: Networks and employment at a phone center[J]. American journal of sociology, 2000, 105(5): 1288-1356.

xviii. Mouw T. Social capital and finding a job: do contacts matter?[J]. American sociological review, 2003: 868-898.

xix. Gali J. Technology, employment, and the business cycle: do technology shocks explain aggregate fluctuations?[J]. American economic review, 1999, 89(1): 249-271.

xx. Uhlig H. Do technology shocks lead to a fall in total hours worked?[J]. Journal of the European Economic Association, 2004, 2(2-3): 361-371.

xxi. Basu S, Fernald J G, Kimball M S. Are technology improvements contractionary?[J]. American Economic Review, 2006, 96(5): 1418-1448.

xxii. Christiano L J, Eichenbaum M, Vigfusson R. What happens after a technology shock?[R]. National Bureau of Economic Research, 2003.

xxiii. Dedola L, Neri S. What does a technology shock do? A VAR analysis with model-based sign restrictions[J]. Journal of Monetary Economics, 2007, 54(2): 512-549.

xxiv. Chari V V, Kehoe P, McGrattan E. Are structural VARs useful guides for developing business cycle theories?[J]. Federal Reserve Bank of Minneapolis, Working Paper, 2004, 631.

xxv. Liu Z, Phaneuf L. Technology shocks and labor market dynamics: Some evidence and theory[J]. Journal of Monetary Economics, 2007, 54(8): 2534-2553.

xxvi. Ming Juan,WangWenfu.Empirical analysis of technological shock, non-technical shock and employment in China[J].Journal of Nanjing Normal University (Social Science Edition),2011(02):72-78.

xxvii. Su Jian,ChenYang.Study on the mechanism of artificial intelligence and other technological progress affecting labor demand[J].China Economic Report,2019(02):75-81.

xxviii. Bellman, R. E. An Introduction to Artificial Intelligence: Can Computers Think? [M]. Boyd \& Fraser Publishing Company, 1978.

xxix. Haugeland J. Artificial intelligence: The very idea[M]. MIT press, 1989.

xxx. Winston, P. H. Artificial Intelligence (Third edition) [M]. Addison-Wesley, 1992.

xxxi. Frey C B, Osborne M A. The future of employment: How susceptible are jobs to computerisation? [J]. Technological forecasting and social change, 2017, 114: 254-280.

xxxii. Felten E W, Raj M, Seamans R. The Variable Impact of Artificial Intelligence on Labor: The Role of Complementary Skills and Technologies[J]. Available at SSRN 3368605, 2019.

xxxiii. Li Xiaoman,ZengXiangquan.New Human Capital Theory-—Research Trends of Ability-based Human Capital Theory[J].Dynamics in Economics,2012(11):120-126.

xxxiv. Cheng Fei.A review of the research on the influence of non-cognitive ability on personal income[J].China Higher Education Research,2013(09):33-38.

xxxv. Hu Bowen. The impact of non-cognitive ability on labor income: mechanism discussion and empirical analysis[D]. Zhejiang University, 2017.

xxxvi. Sheng Weiyan,HuQiuyang.Cognitive ability, non-cognitive ability and skill premium-—an empirical study based on CFPS 2010-2016 micro data[J].Shanghai Economic Research,2019(04):28-42.

xxxvii. Xu Xiaojun.The dual mechanism in the process of employment of college students: human capital and social capital[J].Youth Studies,2002(06):9-14.

xxxviii. ZhengJie.Family Socioeconomic Status and Employment of College Students-—A Perspective of Social Capital[J].Journal of Beijing Normal University (Social Science Edition),2004(03):111-118.

xxxix. Lai Desheng,MengDahu,SuLifeng.Replacement or Complementarity- -A Study on the Joint Mechanism of Human Capital and Social Capital in the Employment of College Students[J].Peking University Education Review,2012,10(01):13-31+187-188.

xl. Organisation for Economic Co-operation and Development (OECD). How good is your job? Measuring and assessing job quality[J]. Employment Outlook 2014, 2014: 79-129.

xli. Huang Guoying,XieYu.The influence of cognitive ability and non-cognitive ability on youth labor income return[J].Chinese Youth Research,2017(02):56-64+97.

xlii. Zhou Guangsu, Fan Gang, Shen Guangjun.Income Gap, Social Capital and Health Level: An Empirical Analysis Based on the Chinese Family Tracking Survey (CFPS)[J].Management World,2014(07):12-21+51+187. 
